\section{Case Reports in Ophthalmology}

Case Rep Ophthalmol 2020;11:668-675

DOI: 10.1159/000510905

Published online: December 21, 2020
(C) 2020 The Author(s)

Published by S. Karger AG, Basel www.karger.com/cop

\title{
Bilateral Spontaneous Hyphema in Juvenile Xanthogranuloma: A Case Report
}

\author{
Abdullah A. Al-Owaid ${ }^{a, b}$ Shaikha Al-Dossaria Azza Maktabi $^{a}$ \\ Deepak Edward $^{a}$ Gorka Sesma $^{a}$ \\ aKing Khaled Eye Specialist Hospital, Riyadh, Saudi Arabia; ${ }^{b}$ Department of \\ Ophthalmology, King Fahd University Hospital, Imam Abdulrahman bin Faisal University, \\ Dammam, Saudi Arabia
}

\section{Keywords}

Hyphema $\cdot$ Juvenile xanthogranuloma $\cdot$ Glaucoma $\cdot$ Touton giant cells

\begin{abstract}
Juvenile xanthogranuloma (JXG) is an idiopathic granulomatous inflammatory condition that usually affects children. Intraocular involvement, especially bilateral, is rare in JXG. Most patients with ocular lesions are typically infants and usually present with hyphema, iridocyclitis, and secondary glaucoma. We report a case of a 3-month-old baby girl who presented to our emergency department with bilateral hyphema that started 3 weeks ago. She was medically free with no history of any recent trauma or preceding febrile illness. General physical examination showed a quiet baby with multiple hyperpigmented macules over the inner thigh and right upper arm, with one pinkish nodule over the occiput. She also had high intraocular pressures. A detailed ophthalmic assessment was done under general anesthesia. The nodular lesion was excised and sent for histopathological evaluation, which confirmed the diagnosis of JXG. Treatment of JXG cases present a challenge to ophthalmologist due to rebleeding and refractory glaucoma. Our case was admitted multiple times for rebleeding and refractory glaucoma and was treated with full antiglaucoma drops, steroid drops and peribulbar injection of steroid.




\section{Case Reports in Ophthalmology}

\section{Introduction}

Juvenile xanthogranuloma (JXG) is a rare, benign, inflammatory histiocytic disorder [1] that presents primarily in infancy. JXG can present at birth, but more than $80 \%$ of the cases present later, within the first year of life [2]. Cutaneous lesions are the most common manifestations, which usually present as brownish papules, mostly in the head and neck region [3]. The most frequent extracutaneous site of involvement is the eye [4]. It has been reported that cutaneous JXG can be associated with ocular JXG in $0.3-0.4 \%$ of cases [5]. Ocular findings in JXG vary widely, from asymptomatic cases to glaucoma and blindness. Ocular involvement is typically seen as an iris nodule, hyphema, and high intraocular pressure. We report this case of bilateral hyphema and high intraocular pressure (IOP) in a 3-month-old child with JXG.

\section{Case Report}

A 3-month-old baby girl presented to our emergency department with bilateral hyphema, which was noticed 3 weeks back. According to the mother, the right eye was first affected, then the left eye 1 week later. There was no history of recent trauma or a preceding febrile illness, no family history of sickle cell anemia or trait, bleeding disorders, glaucoma, or poor vision since childhood.

A general physical examination was done in the emergency room. The baby was quiet and active. Multiple hyperpigmented macules were seen over the inner thigh and right upper arm, with one pinkish nodule over the occiput measuring about $1 \mathrm{~mm}$ in size (Fig. 1a). There were no signs of physical abuse. An ophthalmic assessment revealed high intraocular pressures of 32 and $36 \mathrm{~mm} \mathrm{Hg}$ in the right and left eye, respectively, measured using a Tonopen. Both eyes had mildly injected conjunctiva, cloudy cornea, deep anterior chambers, with a yellowish membrane covering the pupil in both eyes. A yellowish growth over the iris was also observed inferonasally, mixed with blood, in both eyes. Blood in the anterior chamber precluded examination of deeper intraocular structures including the lens and the fundus (Fig. 1b-d).

The rest of the physical examination was unremarkable. The child was in good general condition. The anterior fontanel was open and flat. The ear, nose and throat examination was normal. There was no lymphadenopathy. Other systemic examination was normal.

We admitted the baby and she was started on topical antiglaucoma drugs, including timolol $0.25 \%$, dorzolamide, latanoprost, and apraclonidine for both eyes. She was also administered steroid (Predforte) drops every $2 \mathrm{~h}$.

On the 2nd day of admission, the child underwent examination under anesthesia and a shaving biopsy of the papular occipital lesion, which was about $1 \mathrm{~mm}$ in size, was performed. Her IOP was $23 \mathrm{~mm}$ Hg in both eyes. Ultrasound biomicroscopy (Fig. 2a, b) revealed narrow angles except superiorly, which could not be ruled out due to fixation, an anteriorly rotated ciliary body, and hyphema in the anterior chamber. Ultrasound B-scan (Fig. 2c, d) was performed bilaterally and was normal. Three days later, we examined her under sedation (EUS) and her IOP was $19 \mathrm{~mm} \mathrm{Hg}$ in both eyes, and the hyphema was found to be resolving. MRI of the brain and orbit (Fig. 2e) was also done to exclude retinoblastoma and other brain abnormalities. The baby was discharged on $0.5 \%$ timolol, prostaglandin (Xalatan), apraclonidine (Iopidine) and steroid (Predforte) drops. Two weeks later, she presented again with high IOP. After consulting our colleagues in the glaucoma division, the baby was admitted and started on oral acetazolamide (Diamox). Two days later, the IOP normalized. At that time, the

\section{Karger'=}




\section{Case Reports in Ophthalmology}

Al-Owaid et al.: Bilateral Hyphema in Juvenile Xanthogranuloma

diagnosis of JXG was confirmed based on histological findings of the biopsied tissue which showed Touton giant cells (Fig. 3). The patient was then discharged, and a follow-up was given within 3 weeks. Yet, she presented again with high IOP and rebleeding in both eyes. On admission, a single dose of peribulbar steroid injection in the form methylprednisolone $10 \mathrm{mg}$ was administered. The IOP normalized and the bleeding resolved after 3 days and the baby was sent home with topical $0.5 \%$ timolol, prostaglandin (Xalatan), apraclonidine (Iopidine) and steroid (Predforte) drops for 1-month duration.

After 1 month, we saw the baby; the bleeding had resolved completely in both eyes and the IOP had normalized with antiglaucoma drops given for 3 months.

After about 5 months of being admitted and readmitted again, the bleeding had now resolved and the IOP is normal. We are still following the child in regular manners.

Histopathologic examination of the biopsied tissue showed a cross-section of the skin lined by hyperkeratotic epidermis. The dermis was infiltrated with histocytes highlighted by CD 68. Few Touton giant cells were observed. The cells were negative for CD1a, factor XIII, Langerin, and S100 stains (Fig. 3).

\section{Discussion}

We reported a case of bilateral spontaneous hyphema in a 3-month-old baby who was diagnosed with JXG. JXG is a benign and uncommon form of non-Langerhans histiocytic inflammatory disorder [1] that is characterized by proliferation of multinucleated giant cells (Touton cells) and macrophages [2]. On the contrary, Langerhans cell histiocytosis is a group of histiocytic disorders characterized by the presence of Langerhans cells [3]. Cutaneous JXG lesions were first reported and described as nevoxanthoendothelioma by McDonaugh in 1909. Blank et al. [4] reported the first case of ocular JXG in 1949 in a child with an iris mass and glaucoma. The presence of inflammatory cells and giant cells suggests that the etiology of JXG could be inflammatory in nature [5]. Chang et al. [6] mention that cutaneous lesions can be found in about $40 \%$ of children with ocular JXG. The usual presentation is a maculopapular lesion, which may be orange, yellow, or pink in color [7]. The skin lesions may vary in size from a few millimeters to about $20 \mathrm{~mm}$ [8]. Cutaneous lesions are commonly seen in the head and neck region. Lesions in the spleen, lung, and the gastrointestinal system are also known to occur.

Hyphema in JXG is usually spontaneous and can be associated with iris nodules, rarely it can present without iris nodules as a diffuse iris infiltration.

Although spontaneous hyphema is a common presenting sign of JXG, it is pertinent to rule out the common causes first. Trauma, retinoblastoma, leukemia and blood dyscrasias can present with hyphema in children [9]. Eyelid and conjunctival JXGs are more benign than iris JXG [10]. Iris lesions usually present with hemorrhage and glaucomatous inflammation, which are severe complications and difficult to treat [11]. JXG can also present as a corneoscleral limbal mass without any cutaneous or systemic manifestations. Hence JXG should be one of the differential diagnosis for a corneoscleral limbal mass in children [12]. Other infrequent sites that have been reported to be involved are the cornea, conjunctiva, episclera, retina, choroid, and optic nerve [13]. Posterior segment involvement in JXG may result in retinal detachment and blindness.

In JXG, immunohistochemistry stains for CD68 and factor XIIIA are strongly positive, while those for CD1a and S-100 are negative [14].

\section{Karger'=}




\section{Case Reports in Ophthalmology}

Al-Owaid et al.: Bilateral Hyphema in Juvenile Xanthogranuloma

Management of JXG varies widely as per the literature. Cutaneous lesions are usually kept on observation, whereas systemic and ocular lesions need stringent follow-up and careful examination to look for possible complications. Corticosteroids, both topical and systemic, radiation therapy, and surgical excision have been reported as possible treatment options for ocular JXG. Over the years, several treatment modalities have been used for JXG, including corticosteroids, low-dose radiotherapy, surgical excision, and, in one case, low-dose methotrexate [15].

\section{Conclusion}

JXG, which is related to a spectrum of histiocytic diseases, is a rare disorder that can affect the eye as the most common extracutaneous involvement. It is a disease of childhood that can present to ophthalmologists with ocular symptoms and signs alone. However, we found a papular lesion that helped us to diagnose this child. A thorough history and examination including skin biopsy, ultrasound biomicroscopy and clinical examination is needed to prevent complications and amblyopia in children with this diagnosis. Our case presented with bilateral bleeding and glaucoma, which are difficult to treat in patients with JXG.

\section{Acknowledgement}

The author would like to acknowledge the assistance of our oculoplastic team, Dr. Ossama Alshaikh and Dr. Hamad Alsulaiman, in doing the biopsy for the child and thus helping with the diagnosis and management of this child.

\section{Statement of Ethics}

Statement of Ethics Consent to publish this case report was obtained to publish this case. An approval from the Institutional Review Board at King Khaled Eye Specialist Hospital was also obtained. Written informed consent was provided by the patient's father to publish this case report and any accompanying images.

\section{Conflict of Interest Statement}

The authors have no conflicts of interest to declare.

\section{Funding Sources}

None.

\section{Karger'}




\section{Case Reports in Ophthalmology}

\begin{tabular}{l|l}
\hline DOI: $10.1159 / 000510905$ & (c) 2020 The Author(s). Published by S. Karger AG, Basel
\end{tabular} www.karger.com/cop

Al-Owaid et al.: Bilateral Hyphema in Juvenile Xanthogranuloma

\section{Author Contributions}

All authors attest that they meet the current ICMJE criteria for authorship. All authors contributed to this case report. Abdullah A. Al-Owaid wrote the introduction and the discussion and helped in writing the history. Dr Shikha Al-Dossary helped in the history taking and examination of the child. Dr. Azza Maktabi and Dr. Deepak Edward helped in the histological studies of this case and Dr. Gorka Sesma helped in the final revision as well writing the discussion of this case.

\section{References}

1 Dehner LP. Juvenile xanthogranulomas in the first two decades of life: a clinicopathologic study of 174 cases with cutaneous and extracutaneous manifestations. Am J Surg Pathol. 2003 May;27(5):579-93.

2 Harvey P, Lee JA, Talbot JF, Goepel JR. Isolated xanthogranuloma of the limbus in an adult. Br J Ophthalmol. 1994 Aug;78(8):657-9.

3 Weitzman S, Jaffe R. Uncommon histiocytic disorders: the non-Langerhans cell histiocytoses. Pediatr Blood Cancer. 2005 Sep;45(3):256-64.

4 Blank H, Eglick PG, Beerman H. Nevoxantho-endothelioma with ocular involvement. Pediatrics. 1949 Sep;4(3):349-54.

5 Kobayashi A, Shirao Y, Takata Y, Wajima R, Nonomura A, Huang AJ. Adult-onset limbal juvenile xanthogranuloma. Arch Ophthalmol. 2002 Jan;120(1):96-7.

6 Chang MW, Frieden IJ, Good W. The risk intraocular juvenile xanthogranuloma: survey of current practices and assessment of risk. J Am Acad Dermatol. 1996 Mar;34(3):445-9.

7 Cypel TK, Zuker RM. Juvenile xanthogranuloma: case report and review of the literature. Can J Plast Surg. 2008;16(3):175-7.

8 Roper SS, Spraker MK. Cutaneous histiocytosis syndromes. Pediatr Dermatol. 1985 Nov;3(1):19-30.

9 Karcioglu ZA, Mullaney PB. Diagnosis and management of iris juvenile xanthogranuloma. J Pediatr Ophthalmol Strabismus. 1997 Jan-Feb;34(1):44-51.

10 Hayashi N, Komatsu T, Komatsu T, Hiroi M, Ueno H. Juvenile xanthogranuloma presenting with unilateral prominent nodule of the eyelid: report of a case and clinicopathological findings. Jpn J Ophthalmol. 2004 Sep-Oct;48(5):435-9.

11 Lewis JR, Drummond GT, Mielke BW, Hassard DT, Astle WF. Juvenile xanthogranuloma of the corneoscleral limbus. Can J Ophthalmol. 1990 Dec;25(7):351-4.

12 Chaudhry IA, Al-Jishi Z, Shamsi FA, Riley F. Juvenile xanthogranuloma of the corneoscleral limbus: case report and review of the literature. Surv Ophthalmol. 2004 Nov-Dec;49(6):608-14.

13 Kalina PH, Bartley GB, Campbell RJ, Buettner H. Isolated neurofibromas of the conjunctiva. Am J Ophthalmol. 1991 Jun;111(6):694-8.

14 Janssen D, Harms D. Juvenile xanthogranuloma in childhood and adolescence: a clinicopathologic study of 129 patients from the kiel pediatric tumor registry. Am J Surg Pathol. 2005 Jan;29(1):21-8.

15 Parmley VC, George DP, Fannin LA. Juvenile xanthogranuloma of the iris in an adult. Arch Ophthalmol. 1998 Mar;116(3):377-9. 
Case Reports in Ophthalmology www.karger.com/cop

Al-Owaid et al.: Bilateral Hyphema in Juvenile Xanthogranuloma
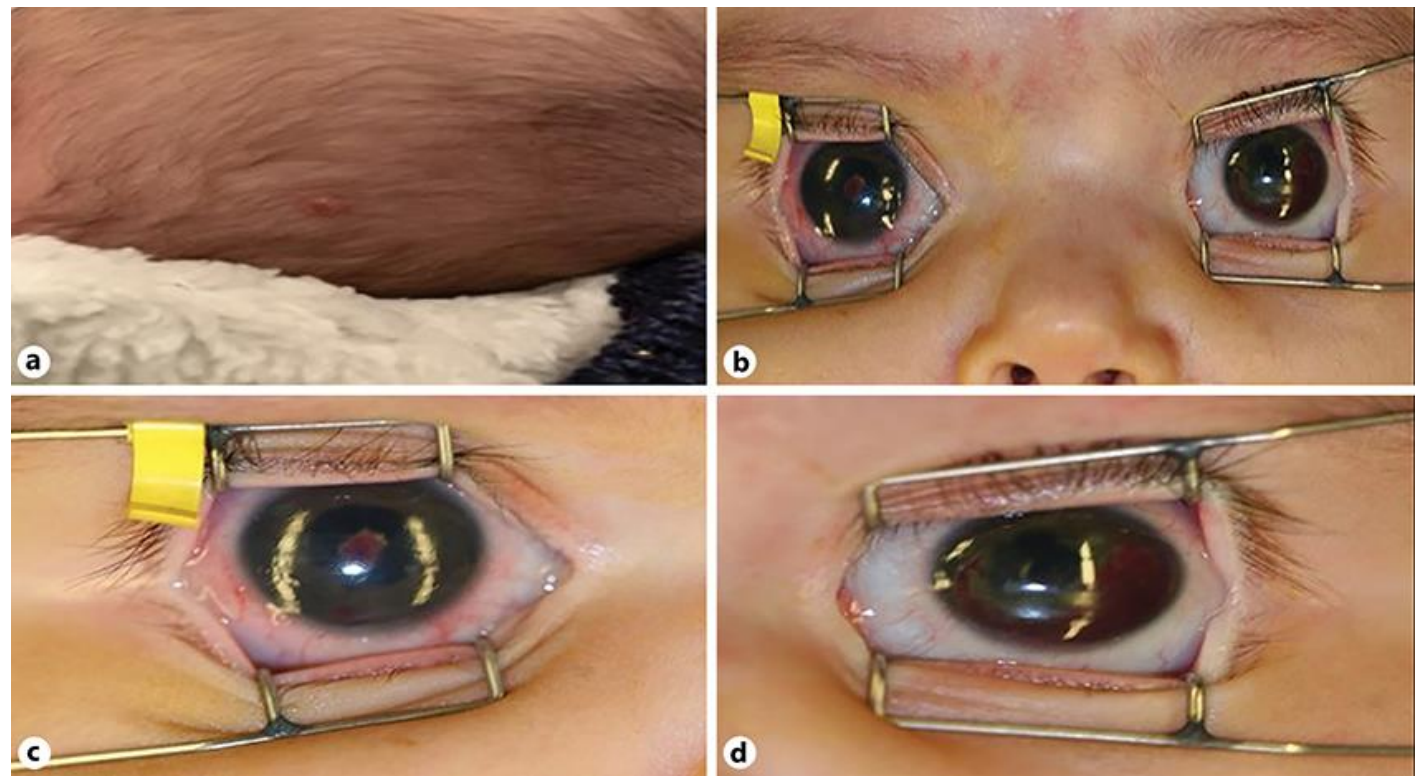

Fig. 1. Clinical photograph of a 3-month-old baby with juvenile xanthogranuloma. a A single, reddish, elevated papular lesion over the occiput of the child. $\mathbf{b}$ Photograph of both eyes, taken in the operating room under general anesthesia showing clinical appearance of bilateral hyphema in the child. c The right eye showed a condensed hemorrhage at the center of the pupil with a yellowish periphery indicating older hemorrhage. $\mathbf{d}$ The left eye showed a dispersed hyphema. 
Case Reports in Ophthalmology
Case Rep Ophthalmol 2020;11:668-675

DOI: $10.1159 / 000510905$

(c) 2020 The Author(s). Published by S. Karger AG, Basel www.karger.com/cop

Al-Owaid et al.: Bilateral Hyphema in Juvenile Xanthogranuloma
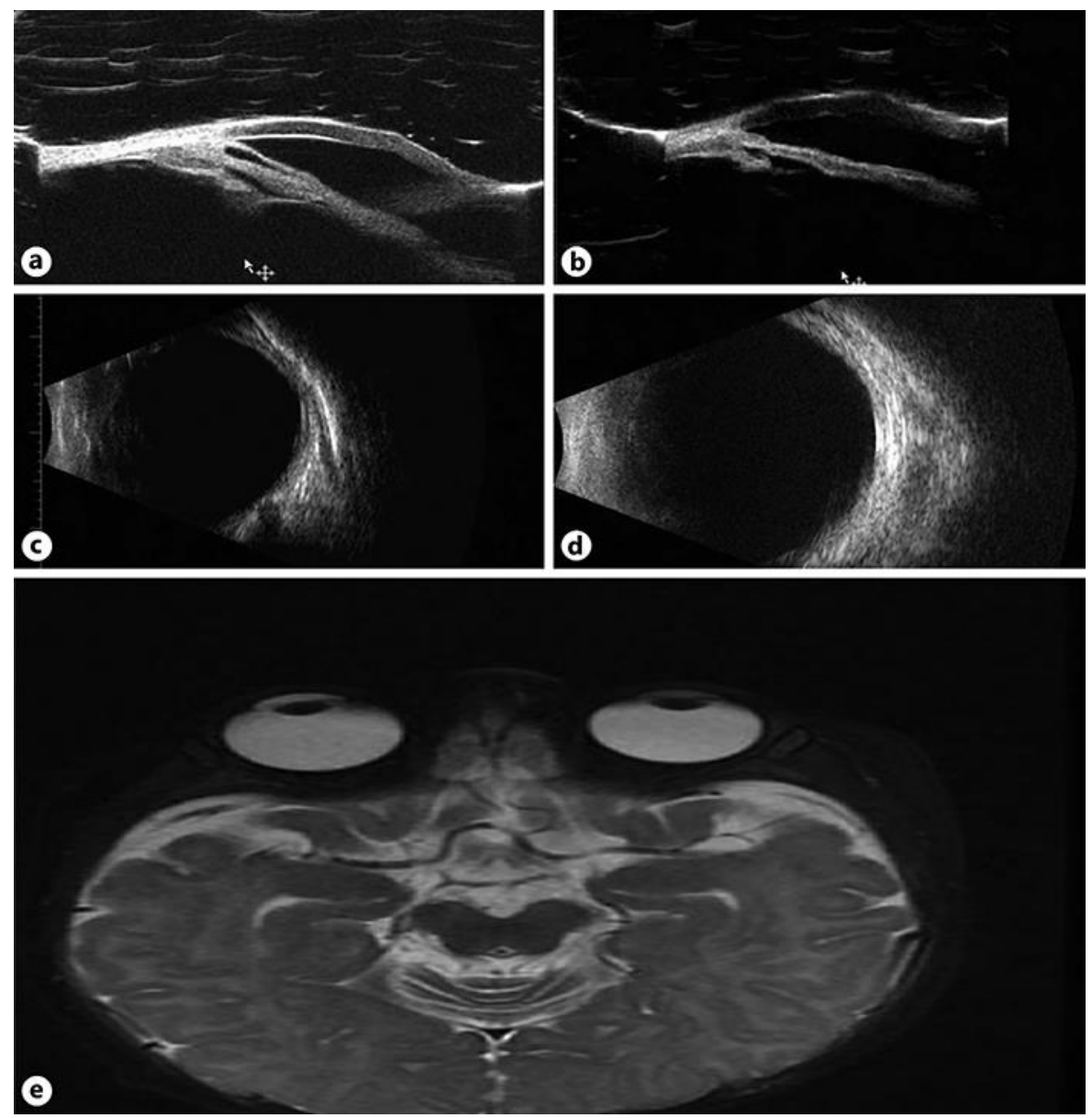

Fig. 2. a, b Ultrasound biomicroscopy of the right and left eyes, respectively, revealed 360-degree narrow angles except superiorly that could not be rolled out due to fixation and anteriorly rotated ciliary body. c, d B-scan ultrasonography of the right and left eyes, respectively, which was normal. e MRI of the brain and orbit with contrast revealed normal orbits and brain parenchyma. 


\section{Case Reports in Ophthalmology}
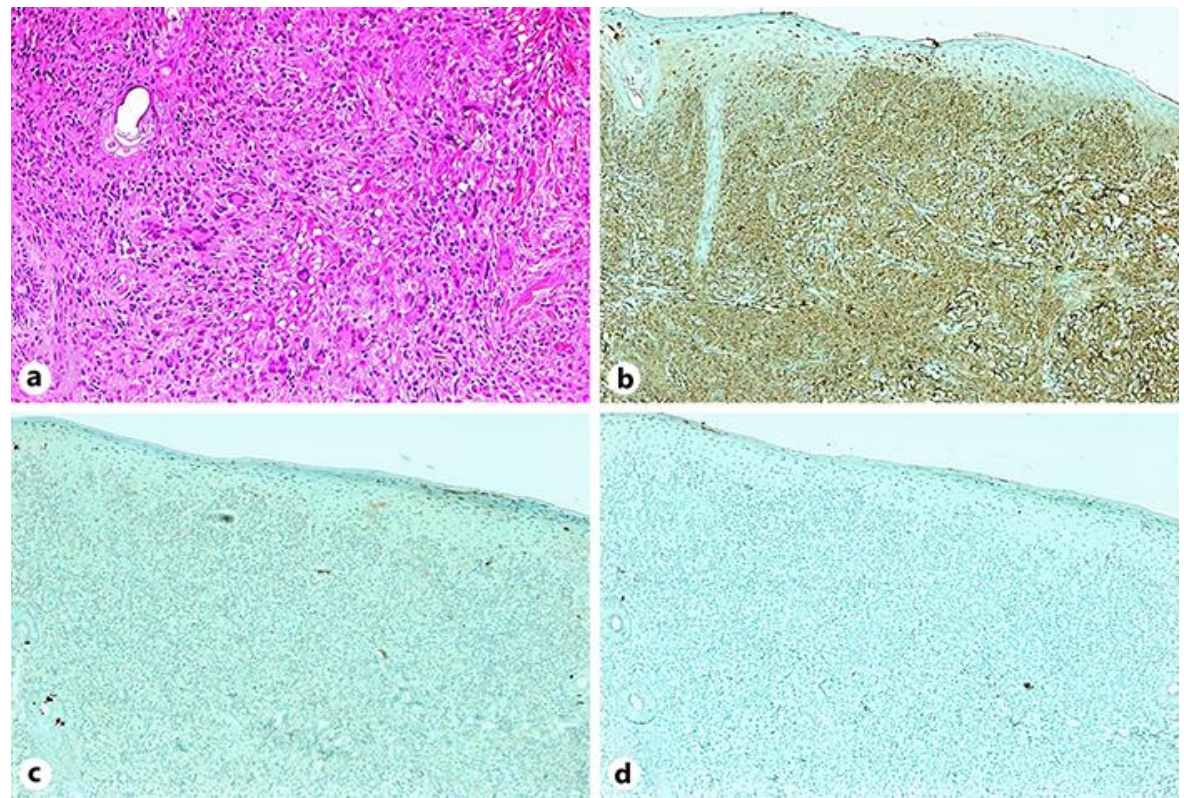

Fig. 3. Histopathological slide images. a Diffuse infiltration with foamy histocytes with few Touton giant cells $($ H\&E. $\times 200)$ b Histocytes are highlighted by CD68 $(\times 100) . \mathbf{c}$, d Cells are negative to Langerin and CD1a (c, d, $\times 100)$. 